\title{
The size-dependent charge fraction of sub-3-nm particles as a key diagnostic of competitive nucleation mechanisms under atmospheric conditions
}

\author{
F. Yu ${ }^{1}$ and R. P. Turco ${ }^{2}$ \\ ${ }^{1}$ Atmospheric Sciences Research Center, State University of New York at Albany, 251 Fuller Road, Albany, \\ New York 12203, USA \\ ${ }^{2}$ Department of Atmospheric and Oceanic Sciences, University of California at Los Angeles, 405 Hilgard Ave, Los Angeles, \\ California 90095, USA
}

Received: 15 March 2011 - Published in Atmos. Chem. Phys. Discuss.: 12 April 2011

Revised: 17 July 2011 - Accepted: 5 September 2011 - Published: 16 September 2011

\begin{abstract}
A clear physical understanding of atmospheric particle nucleation mechanisms is critical in assessing the influences of aerosols on climate and climate variability. Currently, several mechanisms have been proposed and are being employed to interpret field observations of nucleation events. Roughly speaking, the two most likely candidates are neutral cluster nucleation $(\mathrm{NCN})$ and ion-mediated nucleation (IMN). Detailed nucleation event data has been obtained in boreal forests. In one set of analyses of these measurements, NCN was suggested as the dominant formation mode, while in another, it was IMN. Information on the electrical charge distribution carried by the nucleating clusters is one key for identifying the relative contributions of neutral and ion-mediated processes under various conditions. Fortunately, ground-breaking measurements of the charged states or fractions of ambient nanometer-sized particles soon after undergoing nucleation are now available to help resolve the main pathways. In the present study, the size-dependent "apparent" formation rates and fractions of charged and neutral particles in a boreal forest setting are simulated with a detailed kinetic model. We show that the predicted "apparent" formation rates of charged and neutral particles at $2 \mathrm{~nm}$ for eight representative case study days agree well with the corresponding values based on observations. In the simulations, the "apparent" contribution of ion-based nucleation increases by up to $\sim$ one order of magnitude as the size of "sampled" particles is decreased from $2 \mathrm{~nm}$ to $\sim 1.5 \mathrm{~nm}$. These results
\end{abstract}

Correspondence to: $\mathrm{F}$. Yu (fangqun.yu@asrc.albany.edu) suggest that most of the neutral particles sampled in the field at sizes around $2 \mathrm{~nm}$ are in reality initially formed on ionic cores that are neutralized before the particles grow to this size. Thus, although the apparent rate of formation of neutral 2-nm particles might seem to be dominated by a neutral clustering process, in fact those particles may be largely the result of an ion-induced nucleation mechanism. This point is clarified when the formation rates of smaller particles (e.g., $\sim 1.5 \mathrm{~nm}$ ) are explicitly analyzed (noting that measurements at these smaller sizes are not yet available), indicating that IMN dominates NCN processes under typical circumstances in the boreal forest cases investigated.

\section{Introduction}

Aerosol particles formed in the atmosphere influence climate directly through scattering and absorption of radiation, and indirectly by acting as cloud condensation nuclei (CCN) that affect cloud properties and precipitation. New particle formation has been observed to occur frequently in many regions of troposphere (e.g., Kulmala et al., 2004a; Yu et al., 2008) and contributes significantly to global particle concentrations and CCN abundances (e.g., Spracklen et al., 2008; Pierce and Adam, 2009; Yu and Luo, 2009; Kazil et al., 2010). The sensitivities of nucleation rates to changes in a number of controlling parameters suggest important physical feedback mechanisms to climate variation associated with changes in particle and precursor emission rates, solar variability, CCN and other factors, through aerosol indirect radiative forcing (e.g., Yu, 2010). In order to accurately assess

Published by Copernicus Publications on behalf of the European Geosciences Union. 
the influences of aerosols on climate, interpret climate history, and project future changes, it is critical to achieve a clear physical understanding of atmospheric particle nucleation mechanisms and key controlling parameters.

Although nucleation phenomena have been intensively studied over the past several decades, and significant progress has been achieved, there are still major uncertainties concerning atmospheric nucleation mechanisms. For example, the relative importance of neutral cluster nucleation $(\mathrm{NCN})$ processes versus ion-mediated nucleation (IMN), under different ambient conditions, remains unresolved. As a case in point, in a boreal forest setting quite different conclusions have been derived from the same measurements regarding the dominance of neutral versus ion-based nucleation. In one series of studies, NCN was identified as the main pathway, with only a small contribution $(\sim 10 \%$ or less) from IMN (e.g., Laakso et al., 2007; Kulmala et al., 2007, 2010; Gagné et al., 2008, 2010; Manninen et al., 2009), whereas in another set of analyses using the same data, IMN was found to be clearly dominant (Yu and Turco, 2007, 2008; Yu et al., 2008; Yu, 2010).

In the present study, we seek to identify the reasons for the striking differences in past interpretations of these specific field data, with the goal of reconciling observations and theory in relation to aerosol formation in boreal forests. As will be demonstrated below, the likely source of differing interpretations appears to originate in the transitory nature of the nucleation process, and the co-evolution of particle embryo size and electrical charge. In Sect. 2, an overview is given of previous attempts to interpret what, up to this point, is the most comprehensive set of data characterizing aerosol nucleation in the lower atmosphere. Section 3 then provides a detailed analysis of the size-dependent apparent formation rates of charged and neutral particles using a model that consistently represents the complex physical relationships involved. The implications of these new results with respect to the relative contributions of neutral versus ion-mediated nucleation are also presented in this section. Conclusions are given in Sect. 4.

\section{Past studies of the dominant nucleation mechanism in a boreal forest}

Kulmala and colleagues (e.g., Kulmala et al., 2007) have carried out a detailed, long-term characterization of nucleation events at a boreal forest site (Hyytiälä, Finland) using a suite of instruments including a chemical ionization mass spectrometer (CIMS), a Differential Mobility Particle Sizer (DMPS), an ion-DMPS, a Balance Scanning Mobility Analyzer (BSMA), an Air Ion Spectrometer (AIS), and the Neutral Cluster and Air Ion Spectrometer (NAIS). This set of coordinated observations provides the most comprehensive data available to date to constrain nucleation theories. Based on their analysis of the electrical-charge states of nu- cleation mode particles $(\sim 3-15 \mathrm{~nm}$ diameter) measured with the ion-DMPS, Laakso et al. (2007) and Gagné et al. (2008) concluded that, while nucleation mode particles were significantly overcharged (relative to the ambient equilibrium charge level resulting from diffusional charging by background ionization) during most of the nucleation events observed ( $>\sim 80 \%$ of the nucleation event days), the average contribution of IMN to total particle formation was relatively small ( $<\sim 10 \%$ of the new particles). By contrast, Yu and Turco (2007), applying a different analytical methodology to the same data, found that the observed level of overcharging of particles in the $3-5 \mathrm{~nm}$ range pointed to a more significant IMN contribution.

Similarly, based on an analysis of four days of multipleinstrument measurements of neutral and charged nanometersized cluster concentrations in Hyytiälä in spring 2006, Kulmala et al. (2007) concluded that neutral nucleation dominates over ion-induced nucleation, at least under the conditions studied. However, Yu et al. (2008, and in published replies to referee's comments), reanalyzed the same observations, finding that a substantial contribution from IMN could not be ruled out. Aiming to resolve these conflicting conclusions with regard to the importance of IMN, Yu and Turco (2008) carried out a more constrained case study of nucleation events characterized in Hyytiälä, utilizing a kinetic nucleation model that accounts for the size-dependent microphysics of neutral and charged clusters. They demonstrated that good agreement could be achieved between the IMN predictions and field data for a wide range of the key parameters, including the overcharging ratio of 3-7 nm particles. On this basis, it was concluded that IMN is likely to be the dominant nucleation mechanism in at least a large fraction of nucleation events at the observational site.

Manninen et al. (2009) extended the analytical approach of Kulmala et al. (2007) to study a more comprehensive set of data lasting $\sim 4$ months (between 6 March and 30 June, 2007, including 54 nucleation event days), and showed that IMN contributed only $\sim 10 \%$ to new particle formation during that period. Using calculated 2-nm particle formation rates at three ground-based measurement sites (Hyytiälä, Finland; Hohenpeissenberg, Germany; and Melpitz, Germany) based on NAIS and AIS data, Kulmala et al. (2010) further concluded that the overall contribution of ion-induced nucleation to atmospheric aerosol formation is small, being typically much less than $10 \%$. Along similar lines, Gagné et al. (2010) analyzed 2 years and 7 months (May 2005 to December 2007) of ion-DMPS data and compared the derived fractions attributed to ion nucleation to fractions calculated using formation rates of charged and neutral particles at $2 \mathrm{~nm}$ as described in Kulmala et al. (2007) and Manninen et al. (2009), when both ion-DMPS and NAIS measurements were available ( $\sim 44$ event days). Gagné et al. (2010) showed that the charge-state classification based on ion-DMPS measurements is generally consistent with the fraction of ioninduced particles inferred using NAIS measurements, and 


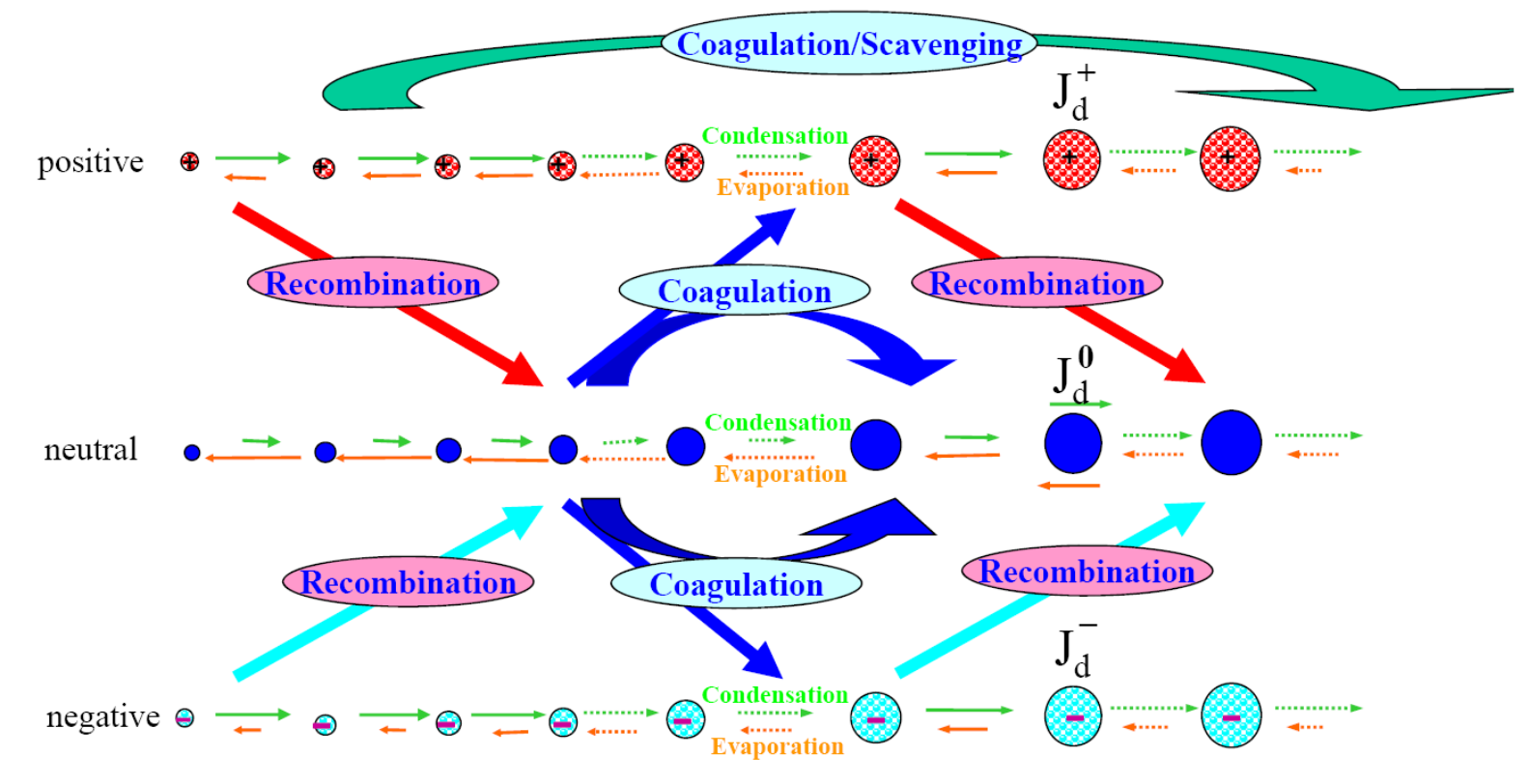

Fig. 1. Schematic illustration of the kinetic processes (condensation, evaporation, coagulation, and recombination) controlling the evolution of positively charged, neutral, and negatively charged clusters/particles that are explicitly simulated in the size-, composition-, and typeresolved ion-mediated nucleation (IMN) model. $J_{d}^{+}, J_{d}^{0}$, and $J_{d}^{-}$are, respectively, the "apparent" formation rate (or net flux) of positively charged, neutral, and negatively charged particles at a given diameter $(d)$. Modified from Yu (2006).

that the two independent measurements indicated $\sim 5-15 \%$ of ion-induced formation of 2-nm particles.

Yu (2010) briefly reviewed these differing studies and pointed out that the importance of IMN would be systematically underestimated when all of the neutral clusters $<2 \mathrm{~nm}$, including those produced by ion-ion recombination (an important channel for IMN, according to Yu and Turco, 2008), are attributed to a purely neutral nucleation process. $\mathrm{Yu}(2010)$ also argued that ion-DMPS data point to a greater significance of IMN when the electrical states of $\sim 1$-nm particles are used as a constraint instead of those of particles $\sim 2 \mathrm{~nm}$ (which tend to be dominated by neutralized ionic clusters, making interpretation of the origin of the particles more difficult). Thus, a key source of differences in the interpretation of the Hyytiälä nucleation data appears to be related to the size-dependent evolution of ionic and neutral clusters in the narrow size range below $2 \mathrm{~nm}$, where nucleation is actually occurring but observations are most difficult. In the following discussion, we refer to the "apparent" nucleation rate of 2-nm particles; this is the rate at which particles of 2$\mathrm{nm}$ size are being formed under local conditions, regardless of the state of electrical charge of those particles. The apparent rate is not the actual nucleation rate, inasmuch as nucleation occurs mainly at embryo sizes well below 2 nanometers. Moreover, it is obvious that the charge state of 2-nm particles is not the same as for newly nucleated particles, which would carry the electrical signature of the nucleation pathway with greater fidelity. Accordingly, the methodology for extrapolating observations taken in the 2-nm range into the smaller size range characterizing the nucleation process itself is critical in interpreting instrumental data.

\section{Size-dependent apparent ion and neutral particle formation rates}

\subsection{Theoretical consideration}

As already noted, new particle formation in the atmosphere is a dynamic process involving various interactions among precursor gas molecules, small clusters (both charged and neutral), and pre-existing particles (Fig. 1). Ions, which are generated continuously and ubiquitously in the atmosphere by cosmic radiation and radioactive decay, interact strongly with common nucleation precursors and thus are inseparable components of the atmospheric nucleation system. Yu and Turco (2001) developed a kinetic approach to study this dynamic system involving neutral and charged clusters, while Yu (2006) substantially improved the detailed treatment of physical, chemical and thermodynamic processes in the version of this model employed here. The model effectively integrates neutral and ionic nucleation processes starting from single molecules, using a discrete-sectional bin structure to represent the size spectra of molecular clusters/particles while accounting for the complex interactions among ions, neutral and charged molecular clusters of various sizes, vapor molecules, and pre-existing particles. The 
differential equations governing the evolution of neutral and charged clusters, along with algorithms to calculate sizedependent rates for various microphysical processes (condensation, evaporation, coagulation, and charge recombination) can be found in $\mathrm{Yu}$ (2006). Below, we describe some of the aspects of these ion mediated nucleation (IMN) simulations that are relevant to the present study.

The evolution of neutral and charged cluster/particle size distributions in the IMN model allows us to calculate the time series of apparent formation rates (or net fluxes, $J$ ) of particles at any given diameter $(d)$. The apparent fraction of nucleation related to ions, $F j_{d}^{\text {ion }}$ is defined as

$F J_{d}^{\text {ion }}=\frac{J_{d}^{+}+J_{d}^{-}}{J_{d}^{+}+J_{d}^{-}+J_{d}^{0}}=\frac{J_{d}^{\text {ion }}}{J_{d}^{\text {ion }}+J_{d}^{0}}$

where $J_{d}^{+}, J_{d}^{0}$, and $J_{d}^{-}$are, respectively, the apparent formation rates (or net fluxes) of positively charged, neutral, and negatively charged particles at a given diameter, $d . J_{d}^{\text {ion }}=$ $J_{d}^{+}+J_{d}^{-}$is the total apparent formation rate of charged particles of diameter $d$.

In addition, the IMN model can track various product and loss terms for particles within given size ranges,

$$
\begin{aligned}
\frac{\mathrm{d} N_{d 1 \_d 2}^{0, \pm}}{\mathrm{d} t} & =\left.\frac{\partial N_{d 1 \_d 2}^{0, \pm}}{\partial t}\right|_{\text {grow }}+\left.\frac{\partial N_{d 1 \_d 2}^{0, \pm}}{\partial t}\right|_{\text {recomb }}+\left.\frac{\partial N_{d 1 \_d 2}^{0, \pm}}{\partial t}\right|_{\text {coag }} \\
& =\mathrm{PL}_{\text {grow }}^{0, \pm}+\mathrm{PL}_{\text {recomb }}^{0, \pm}+\mathrm{PL}_{\text {coag }}^{0, \pm}
\end{aligned}
$$

where $N_{d 1 \_d 2}^{0}$ and $N_{d 1}^{ \pm} \_d 2$ are the concentrations of neutral and charged particles within the size range spanning $d_{1}$ and $d_{2} . \mathrm{PL}_{\text {grow }}^{0, \pm}, \mathrm{PL}_{\text {recomb }}^{0, \pm}$, and $\mathrm{PL}_{\text {coag }}^{0, \pm}$ are production or loss rates associated with growth (or evaporation), recombination, and coagulation, respectively. Recombination, a special case of coagulation, leads to the loss of two oppositely charged clusters/particles while generating one neutral cluster/particle. The attachment of ions/charged clusters to neutral particles, which transforms the neutral particles into charged ones, is included in $\mathrm{PL}_{\text {coag }}^{0, \pm} . \mathrm{PL}_{\text {coag }}^{0, \pm}$ also takes into account selfcoagulation and coagulation scavenging of small clusters by pre-existing particles of same type. $\mathrm{PL}_{\text {grow }}^{0, \pm}$ describes the net fluxes of particles crossing bin size boundaries $d_{1}$ and $d_{2}$, and is related to apparent particle formation rates $\left(J_{d}^{0, \pm}\right)$ as,

$$
\begin{aligned}
\mathrm{PL}_{\text {grow }}^{0, \pm} & =\left(\frac{\mathrm{d} N}{\mathrm{~d} d}\right)_{d 1}^{0, \pm}\left(\frac{\mathrm{d} d}{\mathrm{~d} t}\right)_{d 1}^{0, \pm}-\left(\frac{\mathrm{d} N}{\mathrm{~d} d}\right)_{d 2}^{0, \pm}\left(\frac{\mathrm{d} d}{\mathrm{~d} t}\right)_{d 2}^{0, \pm} \\
& =\left(\frac{\mathrm{d} N}{\mathrm{~d} d}\right)_{d 1}^{0, \pm} \mathrm{GR}_{d 1}^{0, \pm}-\left(\frac{\mathrm{d} N}{\mathrm{~d} d}\right)_{d 2}^{0, \pm} \mathrm{GR}_{d 2}^{0, \pm} \\
& =J_{d 1}^{0, \pm}-J_{d 2}^{0, \pm}
\end{aligned}
$$

where $\frac{\mathrm{d} N}{\mathrm{~d} d}$ is the particle size distribution and $\mathrm{GR}_{d}^{0, \pm}$ is the net particle growth rate at $d$.
By combining Eqs. (2) and (3) and rearranging terms, we have,

$$
\begin{gathered}
J_{d 1}^{0, \pm}=\frac{\mathrm{d} N_{d 1 \_d 2}^{0, \pm}}{\mathrm{d} t}-\mathrm{PL}_{\mathrm{recomb}}^{0, \pm}-\mathrm{PL}_{\text {coag }}^{0, \pm}+\left(\frac{\mathrm{d} N^{0, \pm}}{\mathrm{d} d}\right)_{d 2} \\
\mathrm{GR}_{d 2}^{0, \pm}
\end{gathered}
$$

$$
\begin{aligned}
J_{d 1}^{\mathrm{tot}}= & J_{d 1}^{0}+J_{d 1}^{ \pm}=\frac{\mathrm{d} N_{d 1 \_d 2}^{\mathrm{tot}}-\mathrm{PL}_{\mathrm{coag}}^{\mathrm{tot}}+\left(\frac{\mathrm{d} N^{0}}{\mathrm{~d} d}\right)_{d 2} \mathrm{GR}_{d 2}^{0}}{} \\
& +\left(\frac{\mathrm{d} N^{ \pm}}{\mathrm{d} d}\right)_{d 2} \mathrm{GR}_{d 2}^{ \pm}
\end{aligned}
$$

The formula connecting apparent particle formation rates at $d_{1}=2 \mathrm{~nm}\left(J_{2}^{\text {ion }}, J_{2}^{\text {tot }}\right)$ with observed number concentrations of charged and total particles between $2-3 \mathrm{~nm}\left(N_{2-3}^{ \pm}\right.$and $\left.N_{2-3}^{\text {tot }}\right)$ (Kulmala et al., 2007; Manninen et al., 2009) can be derived (with approximations discussed below) as,

$J_{2}^{\text {ion }}=\frac{\Delta N_{2-3}^{ \pm}}{\Delta t}-\mathrm{PL}_{\mathrm{recomb}}^{ \pm}-\mathrm{PL}_{\mathrm{coag}}^{ \pm}+\frac{N_{2-3}^{ \pm}}{1 \mathrm{~nm}} \mathrm{GR}_{3}^{ \pm}$

$J_{2}^{\mathrm{tot}}=\frac{\Delta N_{2-3}^{\mathrm{tot}}}{\Delta t}-\mathrm{PL}_{\mathrm{coag}}^{\mathrm{tot}}+\frac{N_{2-3}^{\mathrm{tot}}}{1 \mathrm{~nm}} \mathrm{GR}_{3}^{ \pm}$

Here, $N_{2-3}^{ \pm}$is the $2-3 \mathrm{~nm}$ charged particle concentration from the AIS and BSMA measurements; $N_{2-3}^{\text {tot }}$ is the 2$3 \mathrm{~nm}$ total (charged + neutral) particle number concentration from the NAIS measurements; and $\mathrm{GR}_{3}^{ \pm}$is the growth rate of charged sub- $3 \mathrm{~nm}$ particles which can be derived from BSMA and AIS ion spectrum (Manninen et al., 2009). Because the field instruments were not able to measure the growth rate of neutral sub-3-nm particles $\left(\mathrm{GR}_{3}^{0}\right)$, the same growth rate for neutral and charged sub-3-nm particles (i.e, $\mathrm{GR}_{3}^{0}=\mathrm{GR}_{3}^{ \pm}$) has been assumed in Eq. (7), an approximation previously used to derive $J_{2}^{\text {ion }}$ and $J_{2}^{\text {tot }}$ from measurements (e.g., Kulmala et al., 2007; Manninen et al., 2009).

With $J_{2}^{\text {ion }}$ and $J_{2}^{\text {tot }}$ derived from measurements according to Eqs. (6) and (7), the apparent fraction of 2-nm particle formation due to ion processes is readily calculated as $F J_{2}^{\text {ion }}=$ $J_{2}^{\text {ion }} / J_{2}^{\text {tot }}$. The values of $F J_{2}^{\text {ion }}$ can also been derived, completely independently, from ion-DMPS measurements of the charge states of freshly nucleated nanoparticles $\sim 3-5 \mathrm{~nm}$ using a reverse analytical approach (Laakso et al., 2007). The conclusions of previous studies concerning the dominance of neutral nucleation processes are mainly based on the derived $F j_{2}^{\text {ion }}$ values. By contrast, with the IMN model, which resolves the dynamic evolution of both charged and neutral clusters/particles, $F J_{d}^{\text {ion }}$ values can be derived at other sizes, revealing the size-dependence of the apparent ion nucleation fraction, leading to a test of the validity of the apparent fraction at $2 \mathrm{~nm}$ as a gauge for the relative importance of ion versus neutral processes. 

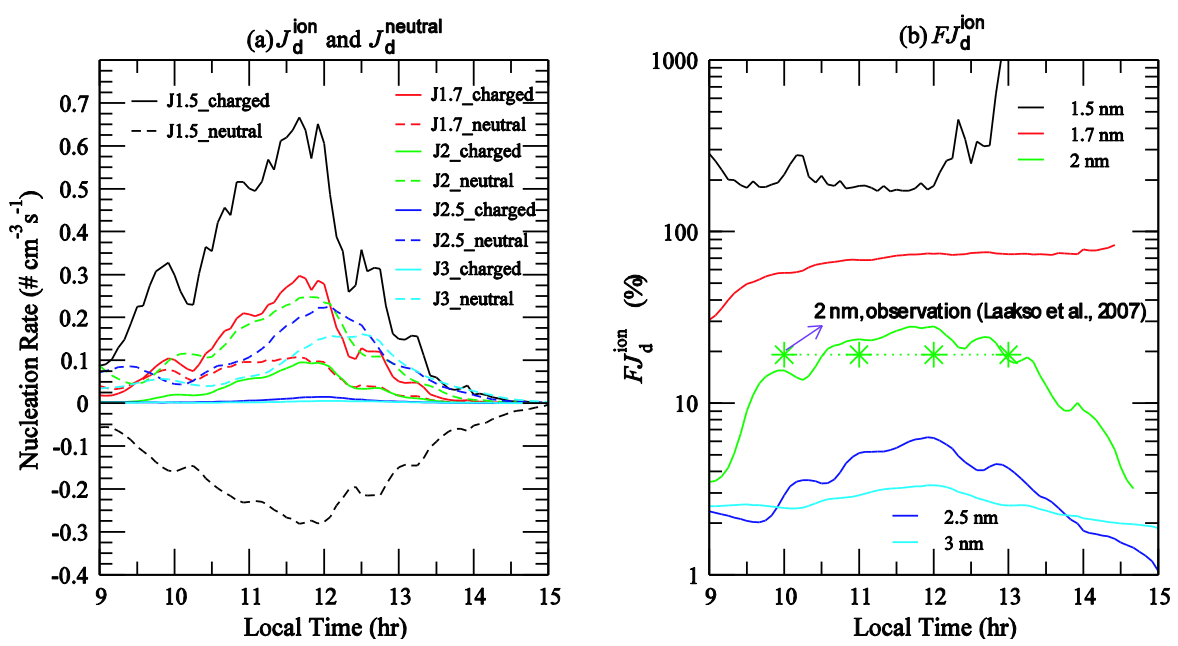

Fig. 2. (a) Predicted evolution of the apparent neutral and charged particle formation rates ( $J_{d}^{0}$ or $J_{d}^{\text {neutral }}$, and $\left.J_{d}^{\text {ion }}\right)$ and (b) the corresponding $F J_{d}^{\text {ion }}$ values at five diameters $(1.5,1.7,2,2.5$, and $3 \mathrm{~nm}$ ) for a nucleation event observed in Hyytiälä on 27 April 2005. The star symbols in panel (b) represent the average $F J_{2}^{\text {ion }}$ value derived from ion-DMPS measurements over the indicated nucleation period on 27 April 2005 (Laakso et al., 2007).

\subsection{Kinetic simulation and comparison with measurements}

Yu and Turco (2008) reported case studies of nucleation events observed during an intensive field campaign at a boreal forest site (Hyytiälä, Finland) in the spring of 2005. Out of the 22 days of the campaign on which nucleation events were observed, eight major events were selected for detailed analysis on the basis of indications that the observed air masses were relatively homogeneous. These selected case study days are representative of the period in terms of meteorological conditions as well as the ranges of $\mathrm{H}_{2} \mathrm{SO}_{4}$ vapor concentrations $\left(\left[\mathrm{H}_{2} \mathrm{SO}_{4}\right]\right)$, apparent particle formation rates, charging ratios, and so on. In a previous study (Yu and Turco, 2008), attention focused on comparisons between IMN model predictions and measured particle number concentrations and the "overcharge ratio" (OR) of freshly nucleated particles (with diameters $\sim 3-6 \mathrm{~nm}$ ). The size-dependent overcharge ratio is the average number of unit electrical charges carried by particles of a given size divided by the equilibrium number of charges that particles of the same size would carry under ambient conditions associated with background ionization rates. In the present study, we calculate the time series of the apparent formation rates of particles at various diameters, $d$, and the apparent fraction of nucleation due to ions $\left(F J_{d}^{\text {ion }}\right)$, based on the simulated evolution of the size distribution of neutral and charged clusters/particles as described in Yu and Turco (2008). The model predicted values of $J_{2}^{\text {ion }}, J_{2}^{\text {tot }}$, and $F J_{d}^{\text {ion }}$ are compared to corresponding measurements reported recently in the literature. Since the particle diameters given in the papers of Kulmala and colleagues correspond to Millikan mobility diameters, we have con- verted the model mass diameters to mobility diameters following the relationship found in $\mathrm{Ku}$ and de la Mora (2009); hence, all the diameters discussed below are equivalent Millikan mobility diameters.

Figure 2 shows the predicted evolution of apparent neutral and charged particle formation rates $\left(J_{d}^{0}\right.$ and $\left.J_{d}^{\text {ion }}\right)$ and the corresponding $F J_{d}^{\text {ion }}$ values at $d=1.5,1.7,2,2.5$, and $3 \mathrm{~nm}$ for a nucleation event observed in Hyytiälä on 27 April 2005. The simulations, as detailed in Yu and Turco (2008), were constrained by observed time series of temperature, relatively humidity, $\left[\mathrm{H}_{2} \mathrm{SO}_{4}\right]$, and the size distribution of preexisting particles. The ionization rate is based on the median value derived from long-term direct measurements reported in Gagné et al. (2010). Figure 2 presents results between 9 am and 3 pm when the air mass was relatively homogeneous, as indicated by consistency in the SMPS data. It is clear from Fig. 2 that $J_{d}^{\text {ion }}$ and $F J_{d}^{\text {ion }}$ decrease significantly as $d$ increases from $1.5 \mathrm{~nm}$ to $3 \mathrm{~nm}$. In contrast, $J_{d}^{0}$ first increases and then decreases as $d$ increases from $1.5 \mathrm{~nm}$ to $3 \mathrm{~nm}$. The dramatic decrease in $J_{d}^{\text {ion }}$ and $F J_{d}^{\text {ion }}$ values as $d$ increases is due to the rapid recombination of charged clusters by oppositely charged small ion clusters. Under the conditions encountered, the neutral $\mathrm{H}_{2} \mathrm{SO}_{4}-\mathrm{H}_{2} \mathrm{O}$ binary nucleation rate is predicted to be essentially zero. Thus, neutral particles are formed solely by recombination processes in this instance, although the apparent neutral particle formation rate dominates at $2 \mathrm{~nm}$. It is interesting to note that $J_{1.5}^{0}$ is negative, which is a result of evaporation of $1.5-\mathrm{nm}$ neutral clusters generated by recombination (based on the thermodynamic properties of very small neutral sulfuric acid droplets, which comprise most of the nucleation embryos prior to the reactive uptake of other vapors). Because of negative values 

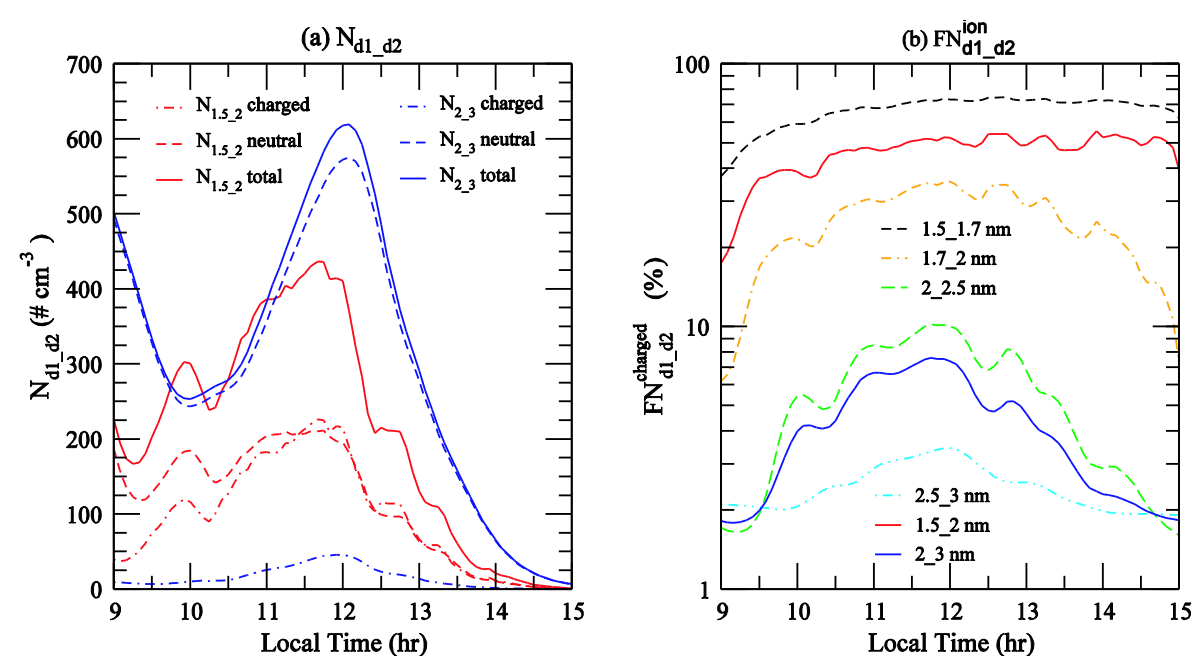

Fig. 3. Corresponding to Fig. 2, IMN simulations for the nucleation event observed in Hyytiälä on 27 April 2005, showing: (a) the number concentrations of neutral, charged, and total particles $\left(N_{d 1 \_d 2}^{\text {neutral }}, N_{d 1 \_d 2}^{\text {ion }}\right.$, and $\left.N_{d 1 \_d 2}^{\text {total }}\right)$ in two sizes ranges $\left(1.5 \_2 \mathrm{~nm}\right.$ and 2_3 nm); and (b) the charged fraction of the total number of particles $\left(F N_{d 1}^{\text {ion }} d 2\right)$ in 6 six size ranges.

for $J_{d}^{0}, F J_{d}^{\text {ion }}=\frac{J_{d}^{\text {ion }}}{J_{d}^{\text {ion }}+J_{d}^{0}}$ can mathematically be larger than $100 \%$. Figure $2 \mathrm{~b}$ shows that $F J_{d}^{\text {ion }}$ decreases from $>100 \%$ at $d=1.5 \mathrm{~nm}$, to $30-70 \%$ at $d=1.7 \mathrm{~nm}$, to $3-25 \%$ at $d=2 \mathrm{~nm}$, and below $6 \%$ at $d=2.5 \mathrm{~nm}$. The $F j_{d}^{\text {ion }}$ value averaged over the nucleation period, as derived from ion-DMPS measurements (Laakso et al., 2007), is $\sim 19 \%$ for this day (assuming an equilibrium charged particle fraction of $0.45 \%$ for $2 \mathrm{~nm}$ particles; Yu and Turco, 2008). It is clear from Fig. 2b that the model predicted $F J_{2}^{\text {ion }}$ values are consistent with the ionDMPS measurements. If one only compares observed and predicted $F J_{2}^{\text {ion }}$ values, and assumes that the original ionic charge survives as a new particle grows to $2 \mathrm{~nm}$, then one may conclude, incorrectly, that $\mathbf{J}_{2}^{\text {ion }}$ only $\sim 19 \%$ of the apparent total 2-nm particle formation rate is due to ion-based processes. This discrepancy becomes obvious when the $F J_{d}^{\text {ion }}$ values at $d=\sim 1.5 \mathrm{~nm}$ are considered, since this is much closer to the critical embryo sizes under the conditions sampled. Indeed, IMN then is clearly seen to dominate particle formation as simulated for this event.

The kinetic IMN model allows the dynamical evolution of neutral and charged clusters of different sizes to be investigated, and the contributions of different microphysical processes to be quantified (i.e., Fig. 1, Eqs. 2 and 3). For the nucleation event on 27 April 2005, Fig. 3 gives the simulated number concentrations of neutral and charged particles in two sizes ranges $(1.5-2 \mathrm{~nm}$ and $2-3 \mathrm{~nm})$, and the corresponding fractions of the total number of particles that are charged. In Fig. 3b, the $1.5-2 \mathrm{~nm}$ and $2-3 \mathrm{~nm}$ size ranges are further divided into four size ranges $(1.5-1.7,1.7-2,2-2.5$, $2.5-3 \mathrm{~nm}$ ) to show more clearly the dependence of charged particle fractions on size. The change in $N_{1.5-2}^{\text {total }}$ generally follows that of $J_{1.5}^{\text {ion }}$ (Fig. 2a), and the peak $N_{1.5 \_2}^{\text {total }}$ value reaches $\sim 425 \mathrm{~cm}^{-3}$, with charged particles accounting for $\sim 50 \%$ of the total (Fig. 3b). $N_{2 \_3}^{\text {total }}$ has a peak concentration of $\sim 625 \mathrm{~cm}^{-3}$ and is dominated by neutral particles (>90\%) at all times. The high sensitivity of the charged particle fraction to size can be seen more clearly in Fig. 3b. During the main nucleation periods, the fraction of charged particles $\left(F N_{d 1 \_d 2}^{\text {ion }}\right)$ decreases from $\sim 70 \%$ for $1.5-1.7 \mathrm{~nm}$ sizes, to $\sim 20-35 \%$ for $1.7-2 \mathrm{~nm}$ particles, to $\sim 5-10 \%$ for $2-2.5 \mathrm{~nm}$ sizes, and to $\sim 2-3.5 \%$ for those $2.5-3 \mathrm{~nm}$. It is not surprising that $F N_{d 1_{-} d 2}^{\text {ion }}$ values (Fig. $3 \mathrm{~b}$ ) are close to those of $F J_{d}^{\text {ion }}$ (Fig. 2b) for particles of similar sizes, as the apparent particle formation rates are proportional to particle number concentrations (Eq. 3).

Figure 4 shows the contributions of different processes (growth, coagulation, and recombination) to changes in the neutral and charged particle concentrations in the $1.5-2 \mathrm{~nm}$ and $2-3 \mathrm{~nm}$ size ranges, $N_{1.5}{ }_{2}$ and $N_{2 \_}$. For charged $1.5-2 \mathrm{~nm}$ particles, growth or nucleation is the only source, while recombination is the main sink. By contrast, for neutral $1.5-2 \mathrm{~nm}$ particles, recombination is the only source, while growth is the main sink. It should be noted that $\left|\mathrm{PL}_{\text {recomb }}^{0}\right|>\left|\mathrm{PL}_{\text {recomb }}^{ \pm}\right|$, which is a result of the production of $1.5-2 \mathrm{~nm}$ neutral particles by the recombination of two sub- $1.5 \mathrm{~nm}$ oppositely charged particles. PL $\mathrm{L}_{\text {grow }}$ for neutral $1.5-2 \mathrm{~nm}$ particles is negative because of the evaporation of $1.5 \mathrm{~nm}$ particles (i.e., negative $J_{1.5}^{o}$ values; see Fig. 2a) while at the same time there is growth-driven removal at $d=2 \mathrm{~nm}$ (i.e., positive $J_{2}^{o}$ values; also see Fig. 2a). The $\mathrm{PL}_{\text {coag }}$ values are negative for both charged and neutral $1.5-2 \mathrm{~nm}$ particles, although their magnitudes (peak values $\sim-0.05--0.1 \mathrm{~cm}^{-3} \mathrm{~s}^{-1}$ ) are much smaller than those of $\mathrm{PL}_{\text {recomb }}\left(-0.45\right.$ and $\left.+0.65 \mathrm{~cm}^{-3} \mathrm{~s}^{-1}\right)$ and $\mathrm{PL}_{\text {grow }}(0.6$ and 

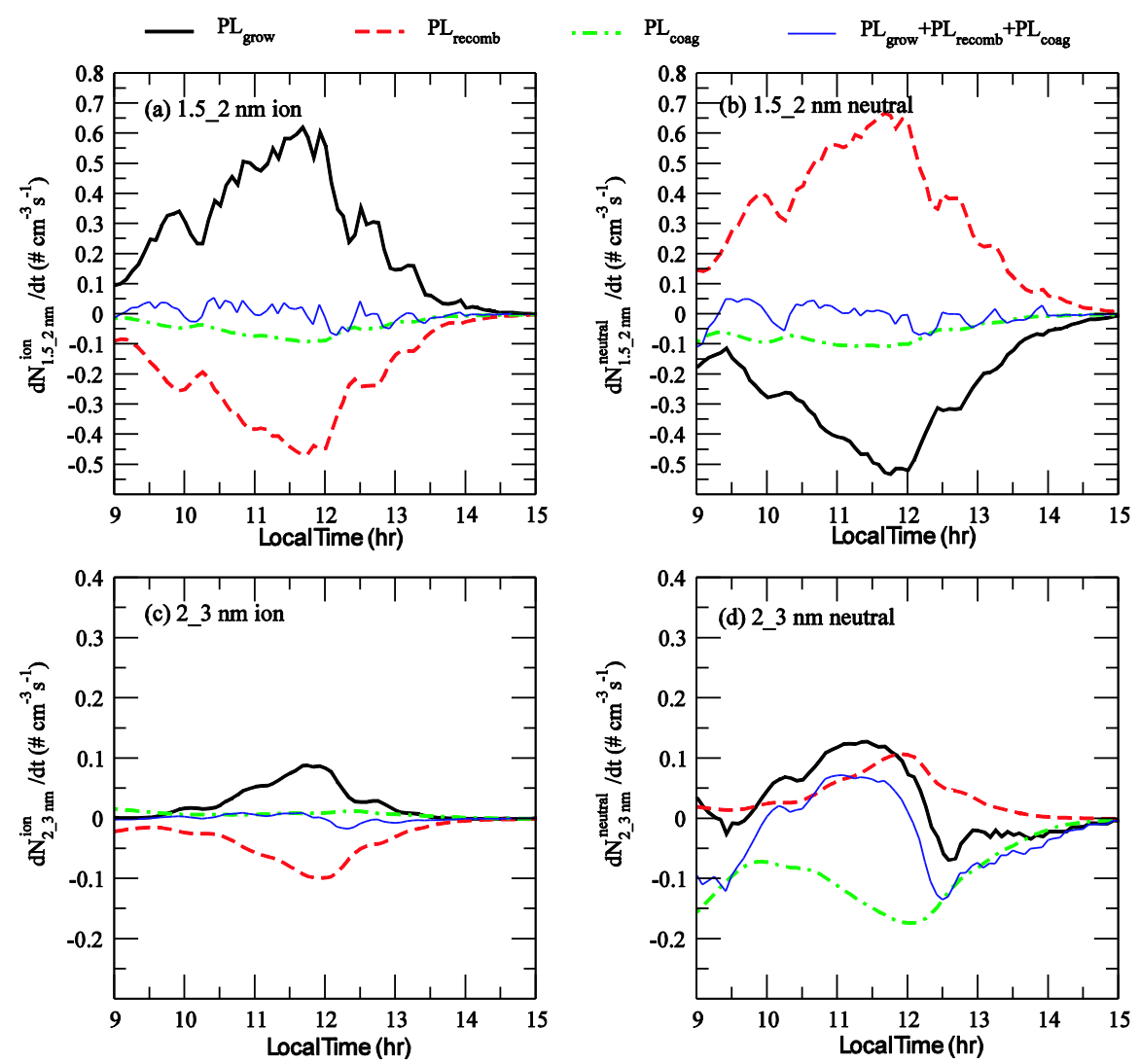

Fig. 4. The contributions of specific processes (i.e., growth, coagulation and recombination) to the changes in neutral and charged particle concentrations in the $1.5-2 \mathrm{~nm}$ and $2-3 \mathrm{~nm}$ size ranges (refer to Figs. 2 and 3, and the text).

$\left.-0.5 \mathrm{~cm}^{-3} \mathrm{~s}^{-1}\right)$. The net rates of change, $\mathrm{d} N / \mathrm{d} t$, fluctuate around zero with an aptitude of $\sim 0.05 \mathrm{~cm}^{-3} \mathrm{~s}^{-1}$, leading to a net increase or decrease in $\mathrm{N}_{1.5-2}$, as shown in Fig. 3a. As the particles grow from $1.5-2 \mathrm{~nm}$ to $2-3 \mathrm{~nm}$, the magnitudes of PL $\mathrm{L}_{\text {grow }}$ and $\mathrm{PL}_{\text {rocomb }}$ decrease by a factor of 4 10. For charged $2-3 \mathrm{~nm}$ particles, growth or nucleation is still the main source, and recombination is the main sink. One interesting point is that, despite coagulation scavenging by larger aerosols, $\mathrm{PL}_{\text {coag }}$ for charged $2-3 \mathrm{~nm}$ particles is slightly positive around noon. Our analysis indicates that this is a result of attachment of small ions to neutral particles. For neutral $2-3 \mathrm{~nm}$ particles, recombination is still a strong source but $P L_{\text {grow }}$ becomes a more important source (i.e., $\mathrm{PL}_{\text {grow }}>\mathrm{PL}_{\text {recomb }}$ ) during the main nucleation period ( $\sim 10$ am-noon). In contrast to $\mathrm{PL}_{\text {grow }}$ for charged $2-3 \mathrm{~nm}$ particles, which is positive during the entire period, $\mathrm{PL}_{\text {grow }}$ for neutral $2-3 \mathrm{~nm}$ particles becomes negative around 12:30 pm because $J_{3}^{o}>J_{2}^{o}$ (i.e., more particles growing above $3 \mathrm{~nm}$ than are growing above $2 \mathrm{~nm}$; see Fig. 3a). $\mathrm{PL}_{\text {coag }}$ is a major sink for neutral $2-3 \mathrm{~nm}$ particles during the entire nucleation period.
Figure 4 shows clearly that neutral particles growing into the 2-nm size range, which are identified with the apparent formation rate of neutral particles at $d=2 \mathrm{~nm}$, were actually generated initially through ion-mediated processes. As before, it must be concluded that the relative importance of ion versus neutral nucleation processes cannot be determined solely on the basis of derived apparent neutral and charged particle formation rates at $d=2 \mathrm{~nm}$. Figures $2-4$ present detailed size-dependent formation rates and number concentrations of sub-3-nm particles for 27 April 2005 (Julian day 117). A similar analysis can be carried out for the other case study days (Julian days \# 102, 103, 108, 122, 123, 132, and 136) described in Yu and Turco (2008). Figure 5 gives the $F j_{2}^{\text {ion }}$ values as a function of hours after sunrise for all 8 of those case study days. For comparison, the symbols represent median values of $F j_{2}^{\text {ion }}$ derived from AIS and NAIS measurements in the spring of 2006 and 2007 on 28 days when particle overcharging was observed (stars) and 8 days with undercharging (diamonds) (from Fig. 2a of Gagné et al., 2010). Undercharging can occur in the presence of rapid neutral nucleation, as particle charging by background ionization will generally lag the equilibrium charge distribution. It should be emphasized that, in Fig. 5, the 


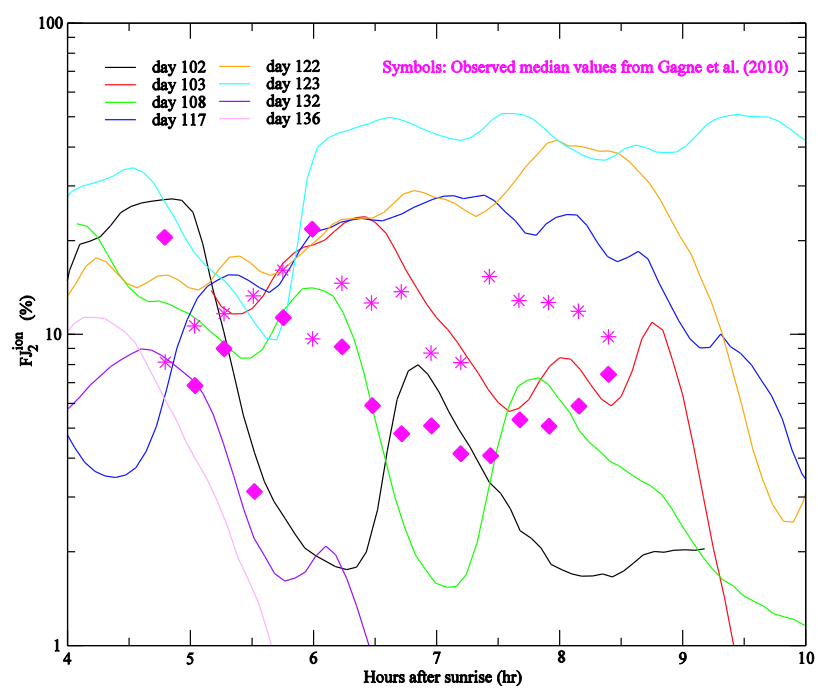

Fig. 5. The apparent fraction of 2-nm particles formed on ions $\left(F J_{2}^{\text {ion }}\right)$ as a function of hours after sunrise for all 8 case study days described in Yu and Turco (2008). Symbols represent the observed median values of $F J_{2}^{\text {ion }}$ obtained by Gagné et al. (2010) (stars: overcharged days; diamonds: undercharged days).

simulations correspond to 8 nucleation events in the Spring of 2005 , while the median values were derived for Spring of 2006 and 2007. IMN model results presented in Fig. 5 show significant day-to-day variations in $F J_{2}^{\text {ion }}$, ranging from a few percent to a few tens of percent. Figure 5 also reveals substantial variations in $F j_{2}^{\text {ion }}$ with local time, implying the sensitivity of averaged $F J_{2}^{\text {ion }}$ values to the averaging period and air-mass inhomogeneity. The median values of simulated $F J_{2}^{\text {ion }}$ for the 8 case study days are $\sim 5-15 \%$ at different local times (or hours after sunrise), and are in reasonable agreement with the observations reported by Gagné et al. (2010). Accordingly, interannual variability does not seem to be a major factor in the comparisons in Fig. 5.

Figure 6 illustrates the mean size-dependent apparent formation rates for both charged $\left(J_{d}^{\text {ion }}\right)$ and neutral $\left(J_{d}^{0}\right)$ particles, and the corresponding $F J_{d}^{\text {ion }}$ values for all eight nucleation events studied by Yu and Turco (2008). The symbols represent the observed median values of $J_{2}^{\text {ion }}=0.08 \mathrm{~cm}^{-3} \mathrm{~s}^{-1}$ (including the formation of $>2-3 \mathrm{~nm}$ particles via ion-ion recombination), $J_{2}^{0}\left(=J_{2}^{\text {tot }}-J_{2}^{\text {ion }}=\right.$ $0.57 \mathrm{~cm}^{-3} \mathrm{~s}^{-1}$ ), and $F J_{2}^{\text {ion }}$ for the Spring of 2007 offered by Manninen et al. (2009). The simulated formation rates and $F J_{d}^{\text {ion }}$ on given days are average values during the periods when nucleation was occurring $\left(J_{1.5}^{\text {tot }}>0.01 \mathrm{~cm}^{-3} \mathrm{~s}^{-1}\right)$. Both $J_{d}^{\text {ion }}$ and $F J_{d}^{\text {ion }}$ decrease exponentially as the particle size increases, a result of the rapid recombination of charged species. For example, $J_{d}^{\text {ion }}$ decreases by up to $\sim$ one order of magnitude as $d$ increases from $1.5 \mathrm{~nm}$ to $2 \mathrm{~nm}$. $J_{1.5}^{0}$ is generally very small and is negative for 6 out of the 8 cases but it increases quickly as a result of increase in neutral clus- ters from ion-ion recombination. $J_{d}^{0}$ and $J_{d}^{\text {ion }}$ are comparable at $d=1.6-1.8 \mathrm{~nm} . J_{d}^{0}$ dominates at $d>\sim 1.8 \mathrm{~nm}$ and is a factor of 5-10 higher than $J_{d}^{\text {ion }}$ at $\mathrm{d}=2 \mathrm{~nm}$ for most of the cases. The predicted median value of $J_{2}^{\text {ion }}$ for the 8 case study days is close to the observed value, although the prediction is for Spring 2005 while the observations were made in Spring 2007. The predicted median value of $J_{2}^{0}$ is $\sim 0.1 \mathrm{~cm}^{-3} \mathrm{~s}^{-1}$ larger than the observed value, but is within the uncertainty range of simulations and observations. The modeled $F J_{2}^{\text {ion }}$ values for the 8 case study days range from $7.6 \%$ to $32.7 \%$, with a median value of $\sim 13 \%$, which is very close to the median of $\sim 12.5 \%$ deduced by Manninen et al. (2009), considering possible uncertainties in both modeling and field observation. For 5 out of 8 case study days, $F J_{2}^{\text {ion }}$ is within the range of $7-15 \%$. On day $123, F J_{2}^{\text {ion }}$ reaches $\sim 32 \%$. It is interesting to note that both NAIS and ion-DMPS measurements show that $F J_{2}^{\text {ion }}$ can be up to 30 $50 \%$ on some days, although the two methods identify different specific days having large fractions, $F j_{2}^{\text {ion }}$ (refer to Fig. $2 \mathrm{~b}$ in Gagné et al., 2010).

The analysis above indicates that, overall, IMN model predictions for $J_{2}^{\text {ion }}, J_{2}^{0}$, and $F J_{2}^{\text {ion }}$ are consistent with equivalent parameters derived from available measurements. Importantly, the inference that the contribution of IMN to particle formation is small $(\sim 10 \%)$ in a boreal forest setting seems to be based on the assumption that the derived "apparent" neutral particle formation rate at $\sim 2 \mathrm{~nm}$ represents the actual neutral nucleation rate. It has been shown above, however, that while IMN indeed contributes $\sim 10 \%$ to the apparent formation rate of 2-nm particles, the actual IMN contribution to particle formation is much greater, and actually dominates nucleation under many common conditions (in instances where the experimental data are homogeneous enough to allow a meaningful time series analysis to be conducted). As pointed out by $\mathrm{Yu}$ (2010), and demonstrated in detail in the present study, most of the neutral particles growing into the 2-nm size range can be formed via ion-based process - in other words, they originate at the molecular embryo level via ion-mediated processes. To properly understand aerosol formation, and determine the contributions of various nucleation mechanisms, an analysis must consider the charged and neutral processes occurring at sizes corresponding to critical embryos, which are generally in the $\sim 1.5 \mathrm{~nm}$ size range (for the Hyytiälä experiments; Kulmala et al., 2007; Yu and Turco, 2008). The exponential decrease of $F J_{d}^{\text {ion }}$ as particle size increases from $d=1.5$ to $2 \mathrm{~nm}$ (Fig. $6 \mathrm{~b}$ ) indicates the significant discrepancy that can arise in basing conclusions about nucleation sources on observations at sizes even slightly larger than the critical embryo (e.g., at $2 \mathrm{~nm}$ rather than $1.5 \mathrm{~nm}$ ). In the present case studies, it happens that the ion-mediated mechanism may account for close to $100 \%$ of all the new particle formation under the conditions of the observations. 

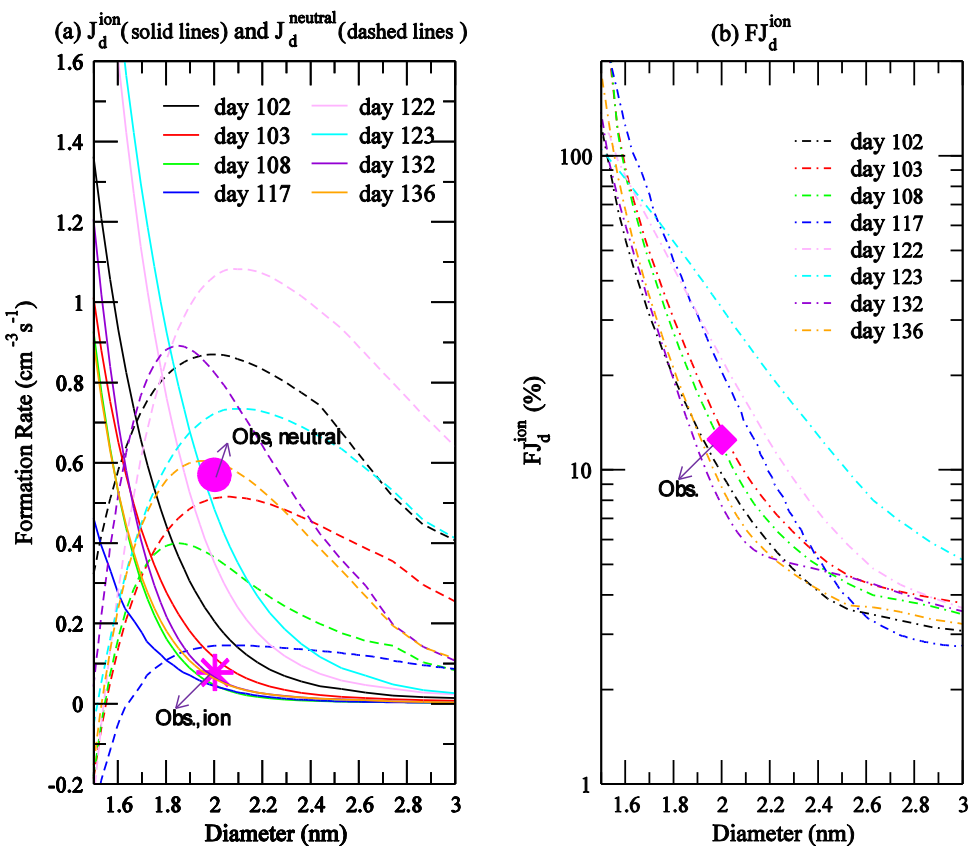

Fig. 6. Mean size-dependent apparent formation rates for both charged ( $\left.J_{d}^{\text {ion }}\right)$ and neutral ( $J_{d}^{\text {neutral }}$ or $\left.J_{d}^{0}\right)$ particles, and the corresponding $F J_{d}^{\text {ion }}$ values, for all eight nucleation events studied by Yu and Turco (2008). The symbols indicate the corresponding observed median values derived by Manninen et al. (2009).

In interpreting the field measurements, proper consideration of ion-ion recombination is critical, since this process effectively determines the rate of neutralization of growing embryos formed on ions, and the stability regime of the recombination clusters, thus affecting the overall contribution of IMN to new particle formation. It should be noted that Manninen et al. (2009) considered ion-ion recombination in their analysis, but only the recombination of ions in the size range of 2-3 nm with ions of opposite sign smaller than $3 \mathrm{~nm}$ (refer to Eq. (2) in Manninen et al., 2009). As shown in the present study, however, most ions may be neutralized before reaching $\sim 2 \mathrm{~nm}$ size. Manninen et al. (2009) further assumed that all of the neutral particles $<2 \mathrm{~nm}$ are formed by neutral nucleation processes whereas detailed simulations suggest these particles are dominated by ion recombination processes (for the corresponding case studies treated here). It turns out that these distinctions are critical to the determination of the actual source of the 2-nm neutral particles, and explains to a large degree inconsistencies between the two interpretations of the intensity of ion-mediated nucleation.

\subsection{Analytical interpretation}

Under certain assumptions, analytical expression describing the evolution of the charging states of nanometer particles can be derived (Kerminen et al., 2007). The exponential decrease of $F j_{d}^{\text {ion }}$ from 1.5 to $2 \mathrm{~nm}$ shown in Fig. 6, which appears to be the key toward understanding the dominant nu- cleation path, has a sound and straightforward physical basis that can be approximately represented using a simplified analytical model. Let us assume that both ion and neutral nucleation processes create thermodynamically stable particles at rates, $J_{d 0}^{\text {ion }}$ and $J_{d 0}^{0}$, respectively, at an initial diameter, $d=d_{0}$. The fraction of new particles that are initially charged (or due to ion nucleation) at $d=d_{0}$ would be given by,

$F J_{d 0}^{\text {ion }}=J_{d 0}^{\text {ion }} /\left(J_{d 0}^{\text {ion }}+J_{d 0}^{0}\right)$

The particles nucleated on ions are subsequently neutralized due to charge recombination during their initial growth phase. Thus, as the particles increase in size from $d_{0}$ to $d_{1}>d_{0}$, the fraction originally nucleated on ions that remain charged is roughly, $e^{-\alpha C^{\Delta} t}$ (also refer to the interactive comments posted by Hellmuth, 2011), where $\alpha$ is the ionion recombination coefficient for a small ion with a charged nanoparticle of opposite sign, $C$ is the total concentration of small (negative or positive) ions, and $\Delta t=\left(d_{1}-d_{0}\right) / \mathrm{GR}$ is the time needed to grow particles from $d_{0}$ to $d_{1}$ at a fixed growth rate (GR).

Assuming that the neutral clusters have same growth rates as the charged clusters, and neglecting coagulation scavenging of clusters as well as ion-neutral attachment, the steady state "apparent" nucleation flux at $d=d_{1}$ for charged particles is,

$J_{d 1}^{\text {ion }}=J_{d 0}^{\text {ion }} \times e^{-\alpha C^{\Delta} t}$ 
Table 1. Fractions of particles that remain charged as particles nucleated on ions at $d=1.5 \mathrm{~nm}$ grow to $d=2 \mathrm{~nm}$ at different particle growth rates (GR's) and concentrations of small ions ( $C$ 's).

\begin{tabular}{lrrr}
\hline & $\mathrm{GR}=1 \mathrm{nmh}^{-1}$ & $\mathrm{GR}=1.9 \mathrm{nmh}^{-1}$ & $\mathrm{GR}=3 \mathrm{~nm} \mathrm{~h}^{-1}$ \\
\hline$C=1500 \mathrm{~cm}^{-3}$ & $1.3 \%$ & $10.3 \%$ & $23.7 \%$ \\
$C=1250 \mathrm{~cm}^{-3}$ & $2.7 \%$ & $15.0 \%$ & $30.1 \%$ \\
$C=1000 \mathrm{~cm}^{-3}$ & $5.6 \%$ & $22.0 \%$ & $38.3 \%$ \\
$C=750 \mathrm{~cm}^{-3}$ & $11.5 \%$ & $32.1 \%$ & $48.7 \%$ \\
$C=500 \mathrm{~cm}^{-3}$ & $23.7 \%$ & $46.7 \%$ & $61.9 \%$ \\
\hline
\end{tabular}

and the "apparent" nucleation flux for neutral particles is

$$
J_{d 1}^{0}=J_{d 0}^{0}+J_{d 0}^{\text {ion }} \times\left(1-e^{-\alpha C^{\Delta} t}\right)
$$

Thus, in this simplified model, the apparent ion nucleation fraction is,

$$
\begin{aligned}
F J_{d 1}^{\text {ion }} & =J_{d 1}^{\text {ion }} /\left(J_{d 1}^{\text {ion }}+J_{d 1}^{0}\right) \\
& =F J_{d 0}^{\text {ion }} * e^{-\alpha C^{\Delta} t} \\
& =F J_{d 0}^{\text {ion }} \times e^{-\alpha C(d 1-d 0) / \mathrm{GR}}
\end{aligned}
$$

It is clear from Eq. (11) that the parameters $C$ and GR have a significant influence on the ratio defining the residual ionnucleation-induced charged particle fraction, $F J_{d 1}^{\text {ion }} / F J_{d 0}^{\text {ion }}$. The median GR values for $1.3-3 \mathrm{~nm}$ "intermediate" ions at Hyytiälä in spring 2007 were estimated using ion mobility spectra to be $\sim 1.9 \mathrm{~nm} \mathrm{~h}^{-1}$ (Manninen et al., 2009). In the IMN model, growth rates vary physically with time and particle size, with the overall values remaining consistent with the observed time delay between increasing concentrations of $\mathrm{H}_{2} \mathrm{SO}_{4}$ in the early morning hours, and the appearance of freshly nucleated particles $(3-6 \mathrm{~nm})$ (Yu and Turco, 2008). The simulated ion concentrations, $C$, for the cases presented in this study are generally in the range of $500-1500 \mathrm{~cm}^{-3}$, with a mean value of $\sim 1000 \mathrm{~cm}^{-3}$. During the corresponding observational period (middle April to middle May), the measured $C$ values according to Fig. 3 in Hirsikko et al. (2005) were also generally in the range of $500-1500 \mathrm{~cm}^{-3}$, with a somewhat lower mean value of $\sim 850 \mathrm{~cm}^{-3}$. The difference in the observed and simulated mean ion concentrations $(\sim 15 \%)$ is reasonable, considering the uncertainties in both simulations and measurements, as well as additional factors associated with diurnal variations (of both measured ionization rates and ion concentrations) and air mass inhomogeneity.

Table 1 summarizes the residual fractions of ion clusters that would remain charged after growth and recombination (i.e., $F J_{d 1}^{\text {ion }} / F J_{d 0}^{\text {ion }}$ ) for different GR's and $C$ 's according to the analytical model above, assuming $d_{1}=2 \mathrm{~nm}, d_{0}=1.5 \mathrm{~nm}$, and $\alpha=\sim 1.6 \times 10^{-6} \mathrm{~cm}^{3} \mathrm{~s}^{-1}$. Depending on GR and $C$, $F J_{2}^{\text {ion }} / F J_{1.5}^{\text {ion }}$ can range from $\sim 1 \%$ to $\sim 60 \%$. This sensitivity to $C$ and GR points to an important source of uncertainty that can impact the accuracy of field data interpretations. However, the most useful observations are typically sufficiently constrained that the actual range of uncertainty for a particular measurement and corresponding simulation is perhaps in the range of a factor of 2-3. The mean analytical predictions for residual ion fractions (or apparent ion nucleation fractions) are also quite consistent with observations, suggesting a fundamental physical consistency in the underlying parameterized model. Further, the more detailed and internally self-consistent IMN model, which takes into account variations in these parameters based on physical principles and supporting measurements, leads to similar reasonable projections.

The simplified analytical model discussed above is also subject to uncertainties associated with the neglect of variations in most parameters with size, and of secondary processes such as differential growth rates, background ionization properties, and so on. Further, in real situations, $\alpha$, and GR depend on the types of particles (charged or neutral), while $\alpha, C$ and GR also vary with time during nucleation events. All of these complexities are taken into account in the kinetic IMN simulations. Nevertheless, both the simplified analytical model and the detailed kinetic IMN model indicate that a substantial fraction (up to $\sim 60 \%-95 \%$ ) of particles nucleated on ions can be neutralized as they grow from $\sim 1.5 \mathrm{~nm}$ to $2 \mathrm{~nm}$ in size. The physics of ion neutralization is straightforward, leading to lifetimes for charged clusters of $\sim 10 \mathrm{~min}$, which is generally shorter than the typical time that it takes such clusters to grow from $1.5 \mathrm{~nm}$ to $2 \mathrm{~nm}$ (for reference, refer to the interactive comments by Hellmuth, 2011).

\subsection{Other constraints on the analysis}

The processes controlling the evolution of nanometer-sized particles and molecular clusters are complex, depend on the compositional nature of the clusters, and are influenced by highly non-linear physical, chemical and thermodynamic processes, some of which are only crudely known for the species of interest. Accordingly, there are inherently a substantial number of sources of uncertainty in any model for atmospheric nucleation.

For example, as discussed in the previous section, the growth rates of $1-3 \mathrm{~nm}$ ion clusters affect charged particle 
fractions in the $2-3 \mathrm{~nm}$ size range. Low volatility organics are known to contribute significantly $(>\sim 80 \%)$ to the growth of particles larger than $3-5 \mathrm{~nm}$ in boreal forests (e.g., Riipinen et al., 2011; Yu, 2011). However, their contribution to the growth of sub- $3 \mathrm{~nm}$ particles is less clear. The condensation properties of these organics depend on their vapor pressures over very small nuclei, which tend to exhibit a large Kelvin effect. Because of this, the condensation of low volatility organics is assumed to be limited to particles larger than $3 \mathrm{~nm}$ in the case studies discussed here (for details, see Yu and Turco, 2008). This assumption is consistent with estimates by Kulmala et al. (2004b) of the particle sizes affected by organics, and with more recent laboratory findings (e.g., Wang et al., 2010). As noted earlier, growth rates associated with $\mathrm{H}_{2} \mathrm{SO}_{4}$ alone are consistent with the observed time delay in the appearance of 3-6 nm particles in the morning hours (see Fig. 3 and Sect. 3.1 in Yu and Turco, 2008). Nevertheless, low volatility organics could be involved under certain conditions, with the magnitude of the effect depending on the relative contribution of low volatility organics versus $\mathrm{H}_{2} \mathrm{SO}_{4}$ (considering, among other factors, organic speciation, differing solubility, and Kelvin effects). Once the contribution, if any, of such species to ion growth is determined, the analysis reported here can be readily updated to include that effect. Lacking specific evidence for the role of organic species at this time, the question of their importance remains open.

Aside from the specific sources of uncertainty mentioned above, this study focuses on the use of additional constraints in developing a more comprehensive theoretical framework for studying nucleation events - in particular the electrical charge carried by particles under atmospheric conditions, and the variations in the charge-states between ambient and nucleating aerosols. While additional constraints are generally helpful, the use of more sophisticated data entails the introduction of variables and parameters that themselves can be uncertain or difficult to quantify. For example, to determine the equilibrium charge on ambient aerosols requires knowledge of the background ionization state, the mobility spectrum of ambient ions, and the accretion kernels for neutral and charged nanometer clusters. Such information, or reasonable estimates for the corresponding parameters, are available, but are not precisely known. Similarly, the coagulation (recombination) kernels for charged clusters/particles over a broad size range can be calculated using basic physical principles, if the condensed matter properties of the particles can be determined. In a long series of papers appearing in the literature, many of these difficulties and uncertainties have been addressed by a number of researchers, both experimentally and theoretically. Nevertheless, we recognize that the additional complexity connected with a combined ionneutral treatment of the nucleation problem invites further sources of uncertainty and error.

The basic line of reasoning that underpins the present analysis recognizes that ions are ubiquitous in the atmosphere, that electrical charge naturally promotes the formation of clusters comprised of the same neutral compounds intimately associated with new particle formation, that particles in dynamic systems will carry electrical charge signatures that can be used to identify competing evolutionary pathways, and that the basic physics along these pathways is well known and long studied under the auspices of classical and quantum chemistry. It follows that a comprehensive theory of nucleation can be formulated and tested against observations. If the comprehensive theory provides explanatory results, then simplified models can be confidently developed by investigating the relative importance of component processes and isolating the most important ones. The converse is not usually true. A simplified model, or highly approximate approach to analysis, cannot generally be extrapolated to reveal more detailed information and reach more fundamental conclusions. Moreover, a comprehensive model can be employed to carry out sensitivity studies that underscore the most critical uncertainties and point to the requirements for new data.

\section{Summary and conclusions}

Nucleation is widely recognized as an important source of atmospheric particles. Accordingly, a clear physical understanding of atmospheric particle nucleation mechanisms is critical to assess accurately the influences of aerosols on climate and to project future climatic change. The relative importance of neutral cluster nucleation $(\mathrm{NCN})$ and ionmediated nucleation (IMN) remains unresolved, even though such processes are currently being integrated into global models.

The results discussed here strongly suggest that ambient atmospheric ionization is intimately involved in the formation of new aerosols under relatively common circumstances, and can explain available multi-instrumental observations of in situ nucleation events. The present investigation, in particular, considers eight well-characterized particle formation events in a boreal forest, employing the latest version of a comprehensive IMN model that explicitly treats NCN as a competitive pathway under atmospheric conditions. The model predicts the size-dependent "apparent" formation rates of charged and neutral particles (or equivalently, the time dependent particle size and electrical charge distributions) that can be compared to values derived from observations. Such comparisons show that, in the cases investigated where field observations were sufficiently well defined to allow time-series simulations, ion-based nucleation processes appear to have dominated particle formation. The analysis also reveals that a clear understanding of the relative effectiveness of ionic versus neutral processes requires a comprehensive treatment of ion-neutral molecular interactions at the smallest nucleation embryo sizes, where measurements are limited and detailed modeling is therefore 
essential. Indeed, the size resolved, charge specific, kinetic analysis described in this paper demonstrates that field measurements can be more accurately interpreted. The results, further, shed light on the likely source of earlier conflicting conclusions regarding the dominance of neutral versus ionmediated nucleation in specific instances; that is, differences in analytical approaches.

While, as noted above, the present analysis is subject to uncertainties associated with thermodynamics, particle growth rates and sizes, and inhomogeneities in air-masses, among other things, these uncertainties are unlikely to alter the general findings reported here, which are based on the well-known physics of electrical charge recombination that, when accounted for in detail, emphasizes the critical role of ions in mediating nucleation processes. Nevertheless, extensive experimental, field, theoretical, and modeling work is needed to reduce the uncertainties in the IMN approach and to assess its ability to explain new particle formation throughout the troposphere. It is important to note that the present investigation does not exclude the likely contributions of neutral nucleation under a variety of atmospheric conditions (especially in highly polluted urban regions), although the exact nature of these nucleation mechanisms remains to be specified. The implication that IMN should generally occur before, and dominate, NCN because of the strong influence of electrical charge on molecular clustering (e.g., Arnold et al., 1982; Yu and Turco, 2001; Lovejoy et al., 2004; Yu, 2006) is tempered, of course, by the limitations associated with ambient ionization rates.

The present research, which demonstrates that an IMN mechanism can successfully explain state-of-the-art multiinstrument field measurements taken in a boreal forest setting, is being applied to other environments. In a recent global application, predictions suggest that ambient ion production rates are large enough to account for many, if not most, of the nucleation events observed worldwide (Yu et al., 2008, 2010). Accordingly, IMN should logically be incorporated into regional and global climate models to improve their ability to predict new particle formation and $\mathrm{CCN}$ abundances, thereby reducing the number of ad hoc assumptions adopted to calculate aerosol indirect radiative forcing, among other particle-related effects.

Acknowledgements. This work is supported by NSF under grant 0942106.

Edited by: K. Lehtinen

\section{References}

Arnold, F., Viggiano, A. A., and Schlager, H.: Implications for Trace Gases and Aerosols of Large Negative Ions Clusters in the Stratosphere, Nature, 297, 371-, 1982.
Gagné, S., Laakso, L., Petäjä, T., Kerminen, V.-M., and Kulmala, M.: Analysis of one year of Ion-DMPS data from the SMEAR II station, Finland, Tellus B, 60, 318-329, 2008.

Gagné, S., Nieminen, T., Kurtén, T., Manninen, H. E., Petäjä, T., Laakso, L., Kerminen, V.-M., Boy, M., and Kulmala, M.: Factors influencing the contribution of ion-induced nucleation in a boreal forest, Finland, Atmos. Chem. Phys., 10, 3743-3757, doi:10.5194/acp-10-3743-2010, 2010.

Hellmuth, O.: Interactive comment on "The size-dependent charge fraction of sub-3-nm particles as a key diagnostic of competitive nucleation mechanisms under atmospheric conditions", Atmos. Chem. Phys. Discuss., 11, C3818-C3818, 2011.

Hirsikko, A., Laakso, L, Hõrrak, U., Aalto, P. P., Kerminen, V.-M., and Kulmala, M.: Annual and size dependent variation of growth rates and ion concentrations in borealforest, Boreal Env. Res., 10, 357-369, 2005.

Kazil, J., Stier, P., Zhang, K., Quaas, J., Kinne, S., O’Donnell, D., Rast, S., Esch, M., Ferrachat, S., Lohmann, U., and Feichter, J.: Aerosol nucleation and its role for clouds and Earth's radiative forcing in the aerosol-climate model ECHAM5-HAM, Atmos. Chem. Phys., 10, 10733-10752, doi:10.5194/acp-1010733-2010, 2010.

Kerminen, V.-M., Anttila, T.,Petäjä, T. , Laakso, L., Gagné, S., Lehtinen, K. E. J., and Kulmala, M.: Charging state of the atmospheric nucleation mode: Implications for separating neutral and ion-induced nucleation, J. Geophys. Res., 112, D21205, doi:10.1029/2007JD008649, 2007.

Ku, B. K. and de la Mora, J. F.: Relation between electrical mobility, mass, and size for nanodrops $1-6.5 \mathrm{~nm}$ in diameter in air, Aerosol Sci. Tech., 43, 241-249, 2009.

Kulmala, M., Vehkamäki, H., Petäjä, T., Dal Maso, M., Lauri, A., Kerminen, V.-M., Birmili, W., and McMurry, P.: Formation and growth rates of ultrafine atmospheric particles: A review of observations, J. Aerosol Sci., 35, 143-176, 2004a.

Kulmala, M., Laakso, L., Lehtinen, K. E. J., Riipinen, I., Dal Maso, M., Anttila, T., Kerminen, V.-M., Hõrrak, U., Vana, M., and Tammet, H.: Initial steps of aerosol growth, Atmos. Chem. Phys., 4, 2553-2560, doi:10.5194/acp-4-2553-2004, 2004b.

Kulmala, M., Riipinen, I., Sipilä, M., Manninen, H. E., Petaja, T., Junninen, H., Dal Maso, M., Mordas, G., Mirme, A., Vana, M.,Hirsikko, A., Laakso, L., Harrison, R. M., Hanson, I., Leung, C., Lehtinen, K. E. J., and Kerminen, V.-M.: Toward direct measurement of atmospheric nucleation, Science, 318, 89-92, 2007.

Kulmala, M., Riipinen, I., Nieminen, T., Hulkkonen, M., Sogacheva, L., Manninen, H. E., Paasonen, P., Petäjä, T., Dal Maso, M., Aalto, P. P., Viljanen, A., Usoskin, I., Vainio, R., Mirme, S., Mirme, A., Minikin, A., Petzold, A., Hõrrak, U., Plaß-Dülmer, C., Birmili, W., and Kerminen, V.-M.: Atmospheric data over a solar cycle: no connection between galactic cosmic rays and new particle formation, Atmos. Chem. Phys., 10, 1885-1898, doi:10.5194/acp-10-1885-2010, 2010.

Laakso, L., Gagné, S., Petäjä, T., Hirsikko, A., Aalto, P. P., Kulmala, M., and Kerminen, V.-M.: Detecting charging state of ultra-fine particles: instrumental development and ambient measurements, Atmos. Chem. Phys., 7, 1333-1345, doi:10.5194/acp-7-13332007, 2007.

Lovejoy, E. R., Curtius, J., and Froyd, K. D.: Atmospheric ioninduced nucleation of sulfuric acid and water, J. Geophys. Res., 109, D08204, doi:10.1029/2003JD004460, 2004. 
Manninen, H. E., Nieminen, T., Riipinen, I., Yli-Juuti, T., Gagné, S., Asmi, E., Aalto, P. P., Petäjä, T., Kerminen, V.-M., and Kulmala, M.: Charged and total particle formation and growth rates during EUCAARI 2007 campaign in Hyytiälä, Atmos. Chem. Phys., 9, 4077-4089, doi:10.5194/acp-9-4077-2009, 2009.

Pierce, J. R. and Adams, P. J.: Uncertainty in global CCN concentrations from uncertain aerosol nucleation and primary emission rates, Atmos. Chem. Phys., 9, 1339-1356, doi:10.5194/acp-91339-2009, 2009.

Riipinen, I., Pierce, J. R., Yli-Juuti, T., Nieminen, T., Häkkinen, S., Ehn, M., Junninen, H., Lehtipalo, K., Petäjä, T., Slowik, J., Chang, R., Shantz, N. C., Abbatt, J., Leaitch, W. R., Kerminen, V.-M., Worsnop, D. R., Pandis, S. N., Donahue, N. M., and Kulmala, M.: Organic condensation: a vital link connecting aerosol formation to cloud condensation nuclei $(\mathrm{CCN})$ concentrations, Atmos. Chem. Phys., 11, 3865-3878, doi:10.5194/acp-11-38652011, 2011.

Spracklen, D. V., Carslaw, K. S., Kulmala, M., Kerminen, V.M.,Sihto, S.-L., Riipinen, I., Merikanto, J., Mann, G. W., Chipperfield, P. M., Wiedensohler, A., Birmili, W., and Lihavainen, H.: Contribution of particle formation to global cloud condensation nuclei concentrations, Geophys. Res. Lett., 35, L06808, doi:10.1029/2007GL033038, 2008.

Wang, L., Khalizov, A. F., Zheng, J., Xu, W., Lal, V., Ma, Y., and Zhang, R.: Atmospheric nanoparticles formed from heterogeneous reactions of organics, Nat. Geosci., 3, 238-242, doi:10.1038/ngeo778, 2010.

Yu, F.: From molecular clusters to nanoparticles: second-generation ion-mediated nucleation model, Atmos. Chem. Phys., 6, 51935211, doi:10.5194/acp-6-5193-2006, 2006.

Yu, F.: Ion-mediated nucleation in the atmosphere: Key controlling parameters, implications, and look-up table, J. Geophy. Res., 115, D03206, doi:10.1029/2009JD012630, 2010.
Yu, F.: A secondary organic aerosol formation model considering successive oxidation aging and kinetic condensation of organic compounds: global scale implications, Atmos. Chem. Phys., 11, 1083-1099, doi:10.5194/acp-11-1083-2011, 2011.

Yu, F. and Luo, G.: Simulation of particle size distribution with a global aerosol model: contribution of nucleation to aerosol and CCN number concentrations, Atmos. Chem. Phys., 9, 76917710, doi:10.5194/acp-9-7691-2009, 2009.

Yu, F. and Turco, R. P.: From molecular clusters to nanoparticles: The role of ambient ionization in tropospheric aerosol formation, J. Geophys. Res., 106, 4797-4814, 2001.

Yu, F., and Turco, R. P.: Charging State of Freshly Nucleated Particles: Implication for Nucleation Mechanisms, in: Nucleation and Atmospheric Aerosols, edited by: O'Dowd, C. D. and Wagner, P. E., Springer, 392-396, doi:10.1007/978-1-4020-6475-3_80, 2007.

Yu, F. and Turco, R.: Case studies of particle formation events observed in boreal forests: implications for nucleation mechanisms, Atmos. Chem. Phys., 8, 6085-6102, doi:10.5194/acp-86085-2008, 2008.

Yu, F., Wang, Z., Luo, G., and Turco, R.: Ion-mediated nucleation as an important global source of tropospheric aerosols, Atmos. Chem. Phys., 8, 2537-2554, doi:10.5194/acp-8-2537-2008, 2008.

Yu, F., Luo, G., Bates, T., Anderson, B., Clarke, A., Kapustin, V., Yantosca, R., Wang, Y., and Wu, S.: Spatial distributions of particle number concentrations in the global troposphere: Simulations, observations, and implications for nucleation mechanisms, J. Geophys. Res., 115, D17205, doi:10.1029/2009JD013473, 2010. 